\title{
Utopía e ironía en el contexto de Tomás Moro ${ }^{1}$
}

\section{(Utopia and irony in Thomas More's context)}

\author{
Juan Antonio SÁNCHEZ \\ Universidad Carolina de Praga \\ sanchez@praha1.ff.cuni.cz
}

Recibido: 16 de mayo de 2011

Aceptado: 20 de junio de 2011

\section{Resumen}

La concepción más común de lo utópico es la de aquella entidad social que, por su misma perfección, no puede darse en la realidad. Esa concepción, que se ha impuesto en el pensamiento moderno y contemporáneo, suele aplicarse, asimismo, a la obra de Tomás Moro, Utopia, en la que se suele ver un estado perfecto pero relegado a la geografía fantástica de lo que podría ser pero nunca será, razón por la cual el humanista ha situado su sociedad en una isla imaginaria. Pero esta concepción olvida los elementos auto-irónicos de la obra de Moro que excluyen una lectura que se pudiera basar en la dicotomía perfección ideal/imperfección real. Ensayamos una lectura, por tanto, más "hermenéutica" de la obra del escritor inglés.

Palabras clave: Moro, Utopía, Erasmo, Bufón, Carnaval, Luciano, Humanismo, Modernidad, Posmodernidad.

\begin{abstract}
The usual conception of the idea of Utopia is that of a social entity that, because of its own perfection, cannot exist in the real world. This conception is preeminent

\footnotetext{
1 Este trabajo se ha realizado gracias a una beca de la Universidad Carolina de Praga. Manifiesto, por tanto, mi agradecimiento a esta institución. (Tento výstup vznikl v rámci projektu 'Mezi utopií a ironii na prahu modernity $v$ zrcadle románské a česky psané literatury' rešeného na Filozofické fakultě Univerzity Karlové v Praze z prostředků specifického vysokoškolského výzkumu na rok 2009 pod čislem 224118.)
} 
not only in modern and contemporary thinking, but also in the interpretations of More's Utopia: according such idea, in the utopian republic, the humanist creates a perfect state, but unreal, and because of that, he places it in the island named noplace. This interpretation forgets the auto-ironical elements in Utopia, whose presence in the work avoids reading it according the scheme ideal perfection-real imperfection. We try a more "hermeneutic" reading of the english humanist's work.

Keywords: Moro, Utopia, Erasmus, Fool, Carnaval, Lucianus, Humanism, Modernity, Posmodernity.

\section{Planteamiento}

Habitualmente se suele concebir la pareja de conceptos utopía-ironía como los dos términos de una dicotomía cuya dinámica interna es la oposición y la exclusión. Lo utópico se entiende como lo ideal, frente a lo irónico, que es lo real, y así podríamos seguir con las correlaciones: lo utópico es lo irreal, lo inexistente, lo irrealizable, lo que no puede encontrarse en el campo inquieto de los acontecimientos humanos (es justamente lo que sugiere el vocablo, inventado por el helenista Tomás

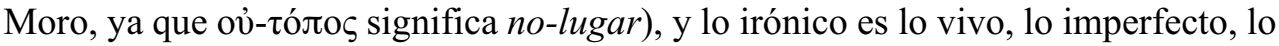
cambiante, lo diferente a sí mismo, que cuenta, sin embargo, con la ventaja de ser palpable, concreto y utilizable, aunque dé problemas. Como, pongamos por caso, la democracia ideal -y utópica- y la democracia que tenemos.

Pero, en su rendimiento aplicable a la sociología, la política y la concepción de la historia, no se trata sólo de una dicotomía equilibrada, sino cinética: uno de los extremos ejerce una fuerza gravitacional sobre el otro. Lo utópico, lo no realizable, sirve de modelo a lo real, que es imperfecto en su intento de realización de lo absoluto -no lograrlo es ser "irónico". Lo ideal se propone, pues, como criterio de lo real, reconduciéndolo y gestionándolo, y dándose a sí mismo como un espejismo a punto de convertirse en una realidad gracias a un movimiento de aproximación infinitesimal, nunca colmada pero ya mediante la promesa válida para el intercambio simbólico.

Pero surgen preguntas y objeciones a las que difícilmente se dará respuesta desde estos presupuestos teóricos. ¿Cómo se alcanza lo ideal? ¿Quién lo propone? ¿No se trata, también, de un desvelamiento que oculta otras cosas, y por tanto, dependiente de su circunstancia, imperfecto? ¿Mediante qué milagroso método se accede a una presencia -lo utópico, lo ideal-que parece libre de las vacilaciones inherentes al proceso comunicativo de producción del significado? Aquello que se propone a sí mismo como modelo heterogéneo de lo real ¿no es ello mismo homogéneo e inmanente respecto de lo real? Es decir, ¿no es lo utópico también discurso, propuesta, producción histórica? Y, por tanto, ¿no es también ironía? 
En el presente trabajo me propongo analizar el estatuto presuntamente "idealizado" de lo utópico en el libro de Tomás Moro, con el que comienza la historia moderna del género. El trasfondo último al que remite este análisis es la crítica de la metafísica de Nietzsche, que, al declarar que "Dios ha muerto", establece una ruptura con la larga tradición occidental que ha pretendido pensar el fenómeno de la verdad como una entidad en sí misma. ${ }^{2}$ Con esta crítica se abre un periodo en el que algunos pensadores buscan una concepción de la verdad que es inseparable de la forma de estar del hombre en el mundo en su actividad dialogística con su entorno. ${ }^{3}$ El ejemplo más evidente es la hermenéutica heideggeriana, en la cual el comprender no es un ejercicio teórico (intellegere) sino una forma de ser del ser-ahí (ein Können, eine Fertigkeit). ${ }^{4}$ Desde este punto de vista, los ideales son sólo una propuesta más, integrante, como otras, del aparato simbólico-histórico-lingüístico en el que el hombre es; propuesta que, en un momento dado, conviene; en otro no. En este ámbito ya no puede decirse que lo utópico sea lo idealmente irrealizable y lo irónico la forma caída de esos ideales en su propia manifestación. Es decir, utopía e ironía compartirían el mismo estatuto ontológico; y esto es precisamente lo que me parece que dice la obra de Moro.

\section{Utopía}

A primera vista, lo inmediatamente expuesto puede resultar chocante porque contradice una concepción clásica de la utopía como género literario en tanto que una Dichtung vom besten Staat, es decir, una ficción o creación poética que representara el estado perfecto. ${ }^{5}$ Pero ¿ciertamente representa la obra de Moro, publicada en 1516, un estado perfecto? Y más aún: ¿lo propone como modelo ideal?

Según Jameson, hay dos lecturas posibles de la obra de Moro, dependiendo de la forma en que se relacionen su primera y segunda parte. Como se sabe, el humanista inglés compuso primero la segunda, donde se describe la isla mítica, y seguidamente la primera, que le sirve como marco a aquélla y en la que se recoge una

\footnotetext{
2 Heidegger (2003), p. 220.

3 Sobre la influencia de Nietzsche en el pensamiento del siglo XX, cf. Kouba (2006), sobre todo el capítulo "Perspektivismus". Ver también, Kouba (2001).

4 Grondin (1991), p. 122. Cf. Heidegger (1977), §§ 4, 5, 6, 31.

5 Biesterfeld (1982), p. 9. Podemos partir de esta definición clara y sencilla a la que podrían añadirse muchas otras en un sentido más o menos correlativo. Por ejemplo, Frank E. Manuel amplía sus límites al considerar dentro del género de lo utópico todo esto: “ 'viajes extraordinarios', informes de viajeros a la luna, descripciones de islas perdidas, constituciones ideales, consejos a príncipes sobre el gobierno más perfecto, novelas construidas en torno a la vida en una sociedad utópica"; cf. Manuel (1982), pp. 103-135. La cita es de la p. 104.
} 
conversación acerca de temas políticos y sociales de la época. ${ }^{6}$ Si damos más importancia a la segunda parte, el elemento de transformación social se mantiene en primer plano; si damos más importancia a la primera parte, podría entenderse que ésta suaviza o matiza el proyecto utópico de la segunda (y para eso la escribiría después). Pero de todas formas, la actitud del autor parece sarcástica o autoirónica, tal y como se puede deducir del sentido paradójico y chistoso y de nombres geográficos como Amaurot o Anider o de personajes como Hythlodaeus o Ademos. ${ }^{7}$ Toda la obra podría leerse como una broma monumental, algo propuesto por Hythlodaeus, el Equivocado, el Absurdo, ${ }^{8}$ y en consonancia con la fama de Moro como gran bromista y con la recomendación de Erasmo a Dropp de leer el libro para pasarlo bien y reírse. ${ }^{9}$ Desde este segundo punto de vista, la lectura de Utopia10 como Dichtung vom besten Staat fracasa, transformándose más bien en la risa que produce dicha pretensión. Ello haría de Moro, en el fondo, un anti-utopista y de su obra una creación fundamentalmente irónica. No estaría proponiendo un estado perfecto susceptible de convertirse en modelo de lo real y, por tanto, en la primera obra de la época moderna del género utópico, no se daría una dialéctica del tipo idealrealidad, sino que, como un bucle, especularía consigo misma acerca de la imposibilidad de desvincular cualquier discurso de su misma contingencia interpretativa.

Sylvester resalta también la dialéctica entre la primera y la segunda parte tal y como se deduce del título doble: ensayo sobre el mejor estado posible y descripción de Utopía. ${ }^{11}$ Tendemos a identificarlas conceptualmente, pero no hay por qué. El primer libro puede verse como tratado político y el segundo dentro de la tradición del relato de viajes como el de Vespucci o, quizá más bien, al estilo del de Mandeville. Moro se preguntaría -irónicamente y jugando- si Utopía es ese estado perfecto del que se habla o al que se alude en el libro I, quedando muy lejos de su identificación no problemática.

\footnotetext{
6 Así se deduce de una carta escrita por Erasmo, en la que el humanista informa de que "Secundum librum prius scripserat per otium, mox per occasionem primum adiecit ex tempore", Erasmo de Rotterdam (1906-1958), p. 21.

7 Jameson (2007), p. 22. Acerca de la cronología de la primera y segunda parte, se puede consultar también Hexter (1952).

8 Sigo la interpretación más habitual del nombre del narrador del viaje, formada a base del elemento hythlos, sinsentido: Nelson (2001), pp. 889-917. No obstante, hay que tener en cuenta que el nombre podría descifrarse igualmente como "Hostile to, destructive to nonsense", o como "merchant, purveyor of nonsense": cf. Wilson (1992), p. 33.

9 Heiserman (1963), p. 164. Recordemos el per otium del comentario de Erasmo tal y como aparece en la nota 6.

10 Utilizo tres grafías: Utopia, en cursiva y sin acento para el título abreviado en latín y aludiendo a la obra concreta de Moro; Utopía, en redonda y con acento para aludir a la isla como lugar ficticio concreto; utopía, en redonda y minúscula, para referirme al concepto de lo utópico.
}

11 Cf. Sylvester (1977). 
En cualquier caso, el relato de Hythlodaeus -o sea, la segunda parte- está directamente conectado con el tema político, pero no para proponer un ideal. Después de que Hythlodaeus haya terminado su larga narración, Moro-personaje comenta el relato en relación con una posible organización política real: es decir, el informe acerca de la isla Utopía se recibe como ejemplo de teoría estatal. Pero el juego irónico consiste en que ese mismo personaje, que se llama como el autor, cree que, con vistas a su aplicación práctica, todo lo dicho es inútil; o sea, que la voz del Moropersonaje cuestionaría todo lo que parece presentarse como "utópico" en el sentido de ideal que no puede aplicarse pero que llevaría a una sociedad perfecta. La pregunta es si se trata esto de la broma final, de un guiño para los amigos, después de exponer lo que verdaderamente importa:

Haec ubi Raphäel recensuit, quanquam haud pauca mihi succurrebant, quae in eius populi moribus, legibusque perquam absurde videbantur instituta, non solum de bellum gerendi ratione, \& rebus divinis, ac religione, alijsque insuper eorum institutis, sed in eo quoque ipso maxime, quod maximum totius institutionis fundamentum est vita scilicet, victuque communi, sinne ullo pecuniae commercio, qua una re funditus evertitur omnis nobilitas, magnificentia, splendor, maiestas, vera ut publica est opinio decora atque ornamenta Reipublicae tamen quoniam defessum narrando sciebam, neque mihi satis exploratum erat, possetne ferre, ut contra suam sententiam sentiretur, praesertim quod recordabar, eo nomine quosdam ab illo reprehensos, quasi vererentur, ne non satis putarentur sapere, nisi aliquid invenirent, in quo vellicare aliorum inventa possent, idcirco $\&$ illorum institutione, \& ipsius oratione laudata, manu apprehendens intro coenarum duco... 12

Algunos críticos han atendido a los componentes irónicos, dialécticos o burlescos de la obra, encontrando en ellos claves fundamentales para entenderla. La importancia de la ironía en Moro es paralela a la de obras como el Elogio de la locu$r a$ de Erasmo. Lo mismo que en esta obra, se diría que todo lo que aparece en la del humanista inglés se dice a la vez en serio y en broma. Los dos amigos, en libelos que parecen escritos con propósitos paralelos, gustan de decir riendo una serie de verdades ( $₫$ o de reirse de las verdades que dicen?). Puede que en el fondo haya una intención didáctica o seria, pero el mecanismo, desde luego, es humorístico. A ese mecanismo, Prevost lo llama la ironía utópica:

L'ironie utopique -qui consiste à dire ou à montrer le contraire de ce que l'on pense afin de mieux fare entendre la vérité profonde. 13

12 Moro (1518), p. 161. Desarrollo las abreviaturas latinas, menos \&, y modernizo en lo más obvio la ortografía.

13 Prevost (1971), p. 161. 
¿Es esta ironía utópica sólo un artificio retórico? ¿Decir lo contrario sólo para mejor exponer una doctrina determinada? Si, como dice Prevost, sirviera para mostrar una verdad profunda, podría diferenciarse netamente entre lo verdadero y lo falso. Pero no es eso lo que encontramos. Desde cierto punto de vista, aquello que parece criticarse no deja de ser bastante aceptable también. Por ejemplo, en el Elogio de la locura, muchos de los aparentes desvaríos de la Moria están llenos de sabiduría práctica. ¿Qué es la locura y qué la razón? parece preguntarse la obra. Un caso que puede aducirse sería la defensa del placer de la Estulticia:

Quid autem vita haec, num omnino vita videtur appellanda, si voluptatem detraxeris? Applausistis. Equidem sciebam neminem vestrum ita sapere, vel desipere magis, imo sapere potius, ut in hac esset sententia. 14

Lo que dice la Locura es aceptado porque nadie es capaz de ser tan sabio (sapere) como para no aceptar que una vida sin placer no es vida (se opone sabiduría y placer). Pero iba a decir que nadie es capaz de ser tan poco sabio (desipere), como para no aceptarlo. Se duda entre sapere y desipere, porque para contrariar la doctrina del placer habría que ser sabio -o sea, lo contrario de la Locura, que habla-, pero también quizá ser loco -porque es verdad que vida sin placer no es vida, y no ser loco en el mundo es locura. ¿Se trata aquí de una ironía retórica según el patrón de Prevost? Sabemos que Erasmo veía con buenos ojos la doctrina epicúrea del placer, aunque fuera dándole una interpretación cristianizada, después de que su maestro Valla hubiera iniciado una revalorización del filósofo del Jardín tras un largo periodo de persecución intelectual. 15 La Moria erasmiana representa tanto la locura de los hombres como la fuerza esencial y autojustificante de las pulsiones de la vida, que se dirigen a un fin más alto que el de la sabiduría (tomada ésta en un sentido teórico), un fin que sirve a las circunstancias concretas de la existencia. En este caso, el autor no está censurando la doctrina del placer en boca de su interlocutor enloquecido, como se censurarían las palabras de un idiota. Tampoco la propone como si fuera aquello en lo que realmente cree. No se trata de introducir una doctrina a través de la ironía. Lo que el humanista ha descubierto es el perspectivismo de la razón. Locura y cordura, absurdo y sabiduría son valores que están en un mundo del cual el hombre tiene experiencia en un acto que es siempre ejercicio de interpretación. Y la cuestión del significado puede alcanzar incluso lo más sagrado. ${ }^{16}$

Apreciaciones parecidas llevan a Blaim a considerar la ironía de Moro -semejante a la de Erasmo- no sólo en tanto que ironía retórica, sino en tanto que una

\footnotetext{
14 Erasmo de Rotterdam (1551), p. 40.

15 Jones (1989), pp. 142 y ss. y esp. 165.

16 Erasmo de Rotterdam (2006), p. 126, Ib 3: "Verum hic de scripturis non est controversia. [...] De sensu scripturae pugna est." Este aspecto ambivalente de la Moria erasmiana lo destaca Kaiser (1963), pp. 25 y ss.; 51 y ss.
} 
especie de autoironía. Moro no criticaría únicamente lo que entrara en contradicción con su mundo supuestamente modelo -si fuera así el concepto de Prevost sería plenamente aplicable- sino que se dirige a menudo contra ese propio mundo que se nos presenta como ejemplo por parte de Hythlodaeus. Por eso Blaim cree que no puede leerse la obra a base de un esquema de dicotomías entre mundo ideal (Utopía) y la Europa o la Inglaterra contemporánea al autor, un esquema que podríamos representar más o menos así:

$\begin{array}{ll}\frac{\text { Utopía }}{\text { virtud }} & \text { Europa } \\ \text { sabiduría } & \text { vicio } \\ \text { libertad } & \text { locura } \\ \text { esclavitud } 17\end{array}$

La numerosa nómina de elementos socialmente absurdos en la sociedad de los amaurotas hace que no pueda tomarse verdaderamente en serio el estado de Utopía en tanto que estado perfecto. Blaim considera una broma el hecho de que los amaurotas, por no estimar el oro ni las piedras preciosas, en un mundo prácticamente regido por el valor de uso, hacen sus ollas y pucheros de barro, reservando el oro para los retretes y para las funciones más sucias del cuerpo:

Ex auro, atque argento non in communibus aulis modo, sed in privatis etiam dominus, matellas passim, ac sordidissima quaeque vasa conficiunt. 18

El mismo narrador considera la historia tan absurda, que tiene miedo de que sea increíble, y se previene con un comentario explicativo:

17 Blaim (1982). La tabla, más amplia, está en la página 10. Acerca de la esclavitud, por ejemplo, podría decirse que en la Utopía moreana era algo aceptado, más o menos como lo era en la Europa de la época, y como también encontramos inquietantemente en la Città del sole ("Non vogliono che schiavi o forastieri infettino la città di mali costumi; però vendono quelli che pigliano in guerra, o li mettono a cavar fosse o far esercizi faticosi fuor della città": Campanella (1962), p. 28. Respecto a la tradición clásica, parece que en la República de Platón se acepta también la esclavitud, aunque sobre esto no existe consenso. Cf. Schlaifer (1936); Cuffel (1966); Vlastos (1968), que defiende que en la República de Platón sí existía la institución de la esclavitud; Calvert (1987), que argumenta contra el anterior, etc. Acerca del tema en la América hispana, se puede consultar el magnífico trabajo de Kř́ižová (2007).

18 Moro (1518) p. 97. Paralelamente, hacen de oro las cadenas para los esclavos: "Ad haec catenas \& crassas compedes, quibus cohercent servos", también en la p. 97. Cf. Bracht (1985), esp. 34. Una burla en este mismo sentido la podemos encontrar en el Gargantúa, cuando éste explica a su padre el material que ha usado para, como él mismo dice, "me torcher le cul": "Une aultre foys d'un cachecoul, une aultre foys des aureillettes de satin cramoysi: mais la dorure d'un tas de spheres de merde qui y estoient m'escorcherent tout le derriere, que le feu sainct Antoine arde le boyau cullier de l'orfebvre qui les feist: et de la damoiselle, que les portoit.”, cf. Rabelais (2007), cap. XIII, p. 139. 
Hanc ob causam inaestimabilem thesaurum servant, at non ut thesaurum tamen, sed ita habent, quomodo me narrare profecto deterret pudor..., ${ }^{19}$

lo cual delata el tono exagerado del chiste, difícilmente comprensible como una propuesta seria de reforma social. Lo mismo podría decirse de la cuestión de la elección de los cónyuges. Según Hythlodaeus, esa elección se hace observándose mutuamente desnudos, para no elegir a alguien que pudiera tener algún fallo disimulado por la ropa. 20

A la luz de este tipo de elementos, que hacen imposible tomar el estado de la isla meramente como modelo sincero de estado perfecto. Por eso Blaim lee la Utopia de Moro en clave polifónica, es decir, como exposición de diversos puntos de vista que nunca convergen y que se hallan en continua incidencia recíproca. Es necesario recordar aquí la interpretación de Sylvester, para quien no existe coincidencia entre las ideas de Hythlodaeus y las del autor, que se relacionarían como agencias en diálogo. 21

Por otra parte, es evidente que se hacen alusiones directas en Utopía, no sólo del libro I, donde es evidente debido al contexto acerca del que hablan los personajes, sino del libro II, con la descripción de la isla, a la Inglaterra histórica y real tal y como la conocían tanto los interlocutores como los primeros lectores. Por ejemplo, la isla es alargada y de medidas semejantes a la Gran Bretaña, y se divide en 54 condados, los mismos que tenía Inglaterra más Gales, contando Londres. ${ }^{22}$ Pero además, la obra está llena de comentarios, tanto del libro I como del II, que tienen una relación directa con el contexto en que vivía Moro. ${ }^{23}$ Según Jameson, el autor puede permitirse la ficción de una república en la que no cuenta el dinero porque en la Inglaterra de 1517, Londres era muy rico y canalizaba el comercio, pero no podía decirse lo mismo del ámbito rural, en una situación todavía muy agraria y poco "capitalizada". ${ }^{24}$ La crítica de los metales preciosos y las joyas puede relacionarse con una escalada en el uso de los mismos tal y como se dio en la corte inglesa de principios de siglo. 25 También se puede relacionar el ataque a las ovejas que aparece en el libro I como una crítica del proceso de privatización de la tierra en favor de los grandes terratenientes y dueños de los rebaños y en detrimento de las propiedades comunales:

\footnotetext{
19 Moro (1518), p. 95.

20 Moro (1518), p. 121: "Mulierem enim seu virgo seu vidua sit, gravis \& honesta matrona proco nudam exhibet [...]"

21 Sylvester (1977), pp. 295 y ss.

22 Harris Sacks (1999), p. 19.

23 Frye (1982) también llama la atención acerca de la relación de Utopia con la sociedad concreta del momento.

24 Jameson (2007), p. 17.

25 Kautsky (1959), pp. 18 y ss.
} 
Oves inquam vestrae, quae tam mites esse, tamque exiguo solent ali, nuc (uti fertur) tam edaces atque indomitae esse coeperunt, ut homines devorent ipsos, agros, domos, oppida vastent ac depopulentur. $[\ldots]^{26}$

Incluso los proyectos comunistas o comunitarios, que han sido considerados tan a menudo como uno de los rasgos básicos de la enseñanza política que se puede extraer de la república de los utopienses, contaban ya con una tradición medieval en la época de Moro. Jean Servier nos habla de John Ball, el clérigo loco de Kent, que, según las Crónicas de Jean Froissart, predicaba en el siglo XIV el comunismo y la erradicación de las clases sociales. ${ }^{27}$

Esta "historicidad" de la obra de Moro demuestra su dependencia respecto de un contexto concreto. Hablando de Utopía, el humanista refleja, de alguna manera, los problemas con los que tendría que enfrentarse cualquier concepción y búsqueda de sentido del mundo que le era contemporáneo. Pero, como todo intento de dar una imagen cabal del espacio vital que se ocupa, su visión no es más que una propuesta personal; y en este caso, es una propuesta hecha con la consciencia de que sólo puede tratarse de una propuesta personal, y de que toda concepción de un mundo se encuentra originalmente enfrentada a otras simultáneas que son siempre susceptibles de influir en el sentido, aplicabilidad, vigencia y alcances de dicha concepción; o, en otras palabras, que se da dentro de un corpus dialogístico de agencias que interactúan unas con otras. De esta manera, por ejemplo, el gusto por el lujo sería seguramente algo que el mismo Moro habría experimentado; luego, el relato de Hythlodaeus parece ridiculizarlo, finalmente, el mismo Moro-personaje vuelve a decir que sin dinero ninguna sociedad es posible. Cualesquiera aseveraciones se dan siempre en el marco de un suelo movedizo y cambiante que las obliga a volverse sobre sí mismas y aparecer siempre bajo una nueva luz. Esta apreciación está en consonancia con la lectura polifónica de Blaim, pero, además, está tematizada en la misma Utopia. ¿De qué manera?

Exponiendo sus ideas sociales, Hythlodaeus invoca la ley evangélica, que prohibe matar, presentándose como un verdadero apóstol del cristianismo. Al oírlo hablar, un abogado, que está presente, decreta que sus propuestas son inaplicables. Sin embargo sucede algo curioso. El cardenal, que también está presente, da la razón al viajero y quienes habían torcido el gesto 28 ante las palabras de Hythlodaeus, ahora, oyendo casi lo mismo pero en boca del que manda, sancionan unánimemente su gran sabiduría. El viajero se da cuenta y lo comenta:

26 Moro (1518), p. 39. Cf. Harris Sacks (1999), pp. 30 y ss. Es interesante comprobar que esta disminución de las propiedades comunales se da también en la Castilla del siglo XVI; cf. Vassberg (1986); también existía en España un problema con la Mesta, que favorecía a los grandes propietarios y que, entre otras cosas, pudo causar la rebelión de las Comunidades; cf. Pérez (2004).

27 Cf. Servier (1969), p. 90. El lugar referido de Froissart es de Les Chroniques de Jean Froissart, París, 1824, vol. VIII, libro II, cap. CVI, p. 15.

28 Literalmente: “distorsit labrum”, en Moro (1518), p. 49. 
Haec ubi dixit Cardinalis, quae me narrante contempserant omnes, eadem nemo non certatim laudibus est prosequutus, maxime tamen illud de erronibus, quoniam hoc ab ipso adiectum est. 29

Tanto Moro como su personaje son conscientes de que la aprobación y el consenso, es decir la determinación práctica de la verdad de un enunciado, no depende, en este mundo, tanto de su contenido como de quién lo enuncia.30 Evidentemente, se trata en primer plano de una crítica social muy del gusto de los humanistas, pero es innegable que existe una consciencia del perspectivismo y sociabilidad de la intercomunicación humana: el lenguaje es un instrumento para situarse en el grupo, por lo tanto su uso se orienta mucho más a la conveniencia práctica del intercambio social que al descubrimiento de la "verdad". Por supuesto, ese perspectivismo tiene su límite en la "ley de Moisés", que ni para Moro ni para Erasmo era una verdad relativa. Pero aparte de eso, incluso en una convivencia supuestamente basada en la moral cristiana, como la de la sociedad de Moro, nada tiene un valor en sí, sino que "valor" es el resultado de un proceso en el que siempre hay dos agencias - o más- en mutua incidencia, de un proceso en el que lo que verdaderamente importa es el efecto práctico y la rentabilidad de los actos valorativos. En un contexto como éste, y con la consciencia de que funciona de tal manera ¿desde qué presupuestos se propone una república perfecta? ¿No sería más bien a trueque de saber que su perfección está condicionada, y por tanto, con la ironía de haber comprendido la imperfección de lo perfecto? ¿No sería como decir la verdad sabiendo que no puede decirse?

\section{El bufón}

Existe todavía otro componente que no podemos pasar por alto para llevar a cabo una lectura completa de la obra de Moro: la presencia del elemento bufonesco, que nos conecta inmediatamente con el carnaval y nos remite a la polifonía bajtiniana -en otro contexto Blaim hablaba también de polifonía. ${ }^{31}$ El tema del loco no estuvo ausente de la literatura medieval, que cuenta con casos conocidos como el de Tristán o el del Merlín enloquecido de la Vita merlinis de Monmouth, la cual, a su vez, puede basarse en antiguas vidas de santos con la misma casuística.32 Pero

\footnotetext{
29 Moro (1518), p. 50.

30 Se relaciona con la idea de la corrupción de los asuntos mundanos, también tematizada en el libro: Moro (1518), p. 64: "Approbanda sunt aperte pessima consilia, \& decretis pestilentissimis suscribendum est."

31 Blaim (1982).

32 Tatlock propone como uno de esos modelos la Vita S. Samsoni, del siglo VIII o IX; cf. Tatlock
} 
es indudable que el tema de la locura cobra una importancia enorme en el imaginario europeo desde fines de la Edad Media. ${ }^{33}$ De hecho, se convierte en la atalaya clave que tiene la racionalidad para contemplarse a sí misma. La locura, como personaje y como tema, es ambigua: sirve para denunciar la sinrazón de la sociedad, cosa que podemos encontrarnos tanto en Erasmo o Moro, como también en Cervantes o Shakespeare; pero por otra parte, su actuación demuestra que en un mundo enloquecido, el loco es precisamente el único que escapa a la insensatez general; y finalmente, acaba planteando preguntas clave acerca de la legitimidad de la razón: supone la toma de consciencia de la carencia de fundamentum inconcussum que tan desesperadamente va a buscar Descartes - precisamente porque es hijo de su época. ${ }^{34}$ En una sociedad degenerada y mentirosa, el loco es el que dice las verdades, o el único que vive como un cristiano; pero en un segundo nivel, se interroga acerca del sentido mismo de la verdad.

En la Utopia de Moro, Libro I, hay una especie de bufón que, de alguna manera, parece pertenecer al séquito del cardenal. Está presente durante toda la conversación, y no interviene hasta el momento en que el monje protesta por la crítica del monacato de Hythlodaeus. En realidad no sabemos si se trata de un bufón, o de una especie de bromista que se hace pasar por bufón, pero en cualquier caso su actuacion es tan perfecta, que puede ser tomado perfectamente por un profesional de la locura:

Adstabat forte parasitus quidam, qui videri volebat imitari morionem, sed ita simulabat, ut propior vero esset, tam frigidis dictis captans risum, ut ipse saepius, quam dicta sua rideretur. 35

(1943), esp. 269. En una versión de otra posible fuente, la Vida de san Kentigern, Merlín aparece asimismo como bufón de la corte del rey Rederech. En opinión de Welsford (1968), pp. 103 y ss., ello demuestra un cruce entre la figura del bufón de corte y el bufón como profeta y clarividente, de origen celta.

33 Foucault (1964), p. 25: “C'est qu'elle symbolise toute une inquiétude, montée soudain à l'horizon de la culture européenne, vers la fin du Moyen Age. La folie et le fou deviennent personnages majeurs, dans leur ambiguité: menace et dérision, vertigineuse déraison du monde, et mince ridicule des hommes." Welsford (1968), pp. 8 y ss. y 128 y ss., habla del extraordinario florecimiento de la figura del bufón en la civilización italiana de finales de la Edad Media y el Renacimiento, mientras que, en la literatura medieval, a veces el caso del bufón, documentable, se reduce antes del siglo XIV a meras menciones (p. 116). En su estela va Kaiser (1963), p. 4. Para un panorama de la literatura bufonesca en la literatura española, se puede consultar Villanueva (1982) y (1985-86).

34 La figura del loco como portador de significados no meramente negativos, es decir, que habría que desterrar del mundo, todavía no está en Brant, para el cual la locura simboliza la degeneración en la que se encuentra el estado de las cosas; cf. Lefebvre (1968), pp. 77 y ss. Para ello hay que esperar a una conjunción de la concepción carnavalesca de la vida con el espíritu lucianesco reivindicado por los humanistas (más adelante en el texto). Sobre la ambivalencia del personaje del loco, cf. Kaiser (1963), p. 10.

35 Moro (1518), p. 50. Sobre el término parásito, usado por Plutarco, cf. Welsford (1968), pp. 3 y ss. 
Rebatiendo al monje, el loco lleva a cabo una crítica del monacato muy del gusto erasmista, y, algo todavía peor, lo asimila a su propia idiotez: ¿quién presta oídos a lo que dice el bufón sino otro como él? Pero además, su mera intervención, el mero hecho de que tome cartas en el asunto, ya está socavando la seriedad de todo lo que se dice acerca de la política de Inglaterra. Es una escena en la que Hythlodaeus ha defendido a los ladrones y el Cardenal a los vagabundos, injerencias que podríamos calificar como utópicas en el sentido de reformas idealizadas; después, enlazando con ellos, el bufón se asigna él mismo el cuidado de los pobres. Este paralelismo los pone a los tres al mismo nivel, a Hythlodaeus, al Cardenal y al loco, demostrando que en ese discurso lo respetable y lo absurdo pueden ser asignaciones intercambiables; o sea, que desvaloriza la intención reformista del narrador y riduculiza la ingenuidad del Cardenal, que parece la figura con más autoridad en el grupo. ¿No hablan, entonces, unos y otros, como si estuvieran todos locos? Podemos traer a colación la anécdota sobre lo que Demócrito dijo a Hipócrates, recogida por Huarte de San Juan, según el cual, lo que vino a decirle fue

que este mundo no era más que una casa de locos, cuya vida era una comedia graciosa representada para hacer reír a los hombres. ${ }^{36}$

Tanto el Elogio de la locura, como la Utopia de Moro son obras humanistas donde se presentan discursos enunciados por boca de la locura. Evidentemente, Hythlodaeus es personaje de la misma estirpe que Moria, otro loco a medias paulino, ${ }^{37}$ cuyas verdades, por una parte, son absurdas quizá lo mismo que lo son las verdades evangélicas, verdades que son locuras en opinión del Apóstol porque lo son para un mundo regido por valores equivocados, los del egoísmo y la ausencia de amor al prójimo y a Dios. Pero, además, las locuras de Hythlodaeus, por otra parte, son absurdas en tanto que inaplicables e inútiles, son como el discurso desatinado de un loco, porque cada cual vive dentro de un universo no extrapolable a la comprensión de los demás: la razón se está convirtiendo en propiedad del individuo, y, por tanto, cada uno tiene la suya, como se queja Descartes al principio de su Discurso.

El mundo es una casa de locos - eso es también lo que se deduce de la segunda aparición de la figura del bufón, esta vez en el libro II y camuflado en una especie de facecia. Se trata del caso de los embajadores anemolios, que, al llegar cargados de piedras preciosas y ricas vestiduras a la isla Utopía, donde tales baratijas se dejan

\footnotetext{
36 San Juan (1989), p. 175.

37 No hay que olvidar que su nombre es Rafael, es decir, etimológicamente, el "sanador" de Dios, es decir un representante del evangelio, como se ha dicho antes al hablar de la ley de Moisés. Cf. Sylvester (1977), p. 296. La asociación del loco con la doctrina paulina ya se daba en la Edad Media. A través de Kempis y Cusa, estas ideas llegan a Erasmo; cf. Kaiser (1963), pp. 8-10.
} 
para los niños o para los esclavos, suscitan la curiosidad de un muchacho que pregunta a su madre, asombrado por ésos que van vestidos de forma tan ridícula. La madre le dice que se calle, que deben ser los bufones de los legados:

At parens serio etiam illa, tace inquit fili, est opinor quispiam e morionibus legatorum. ${ }^{38}$

Embajador $=$ Bufón. Los hombres de mundo, fácilmente reconocibles por los lectores de Moro, los grandes señores de vestiduras suntuosas, no se consideran, desde la perspectiva de Utopía, ese espejo deformante-ampliante, esa lupa para ver mejor, más que como seres ridículos, un poco despreciables pero al mismo tiempo provocadores de una especie de conmiseración y vergüenza que obliga a hablar de sus taras en voz baja. El bufón es la operación simbólica que demuestra la reversibilidad de los valores.

Las dos manifestaciones bufonescas detectables en la obra nos llevan, por una parte, a la crítica del mundo "real" a través del ejemplo invertido de Utopía; pero, por otra parte, como todo discurso pronunciado por el bufón, cualesquiera verdades que se enuncian se ven al mismo tiempo subsumidas en su propia bufonería, es decir, es una voz siempre dispuesta a reírse de sí misma, a reírse de todo, con una risa liberadora y disolvente que declara la carencia de fundamento de las elecciones humanas. Esa risa es, por una parte, la risa carnavalesca, y aquí hay que recordar la relación entre carnaval y locura, estudiada por Bajtin, y que podemos ver ilustrada en el cuadro de Brueghel; por otra, es también la risa menipea de raigambre cínica, es la risa del Perro dentro de su tinaja -y no hay que olvidar que Demócrito, citado por Huarte de San Juan, es precisamente un atomista que niega la providencia y que influirá en Epicuro.

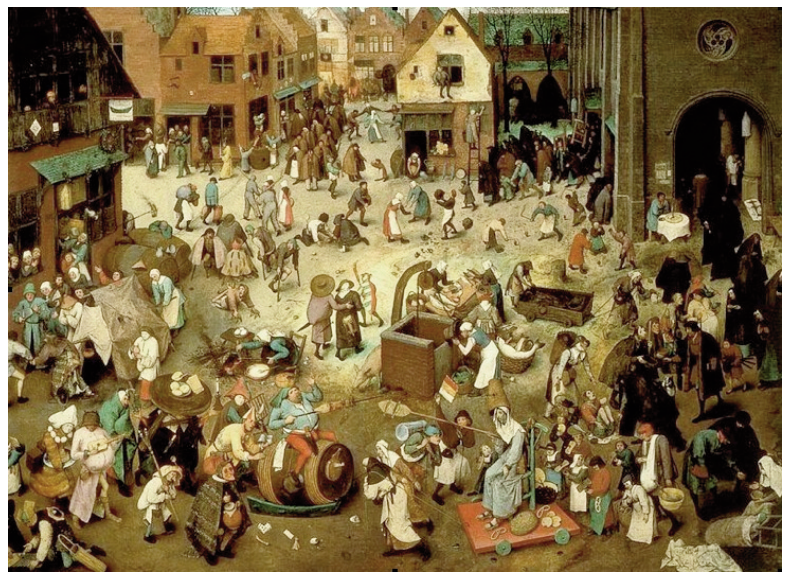

Brueghel, El combate de don Carnaval y doña Cuaresma, 1559.

38 Moro (1518), p. 99. 
Sabemos que Moro y Erasmo tradujeron juntos, como si se tratara de una especie de juego intelectual, a uno de los escritores antiguos más determinantes para el siglo XVI: Luciano de Samosata. La moderna moda lucianesca comienza gracias al manuscrito griego con algunas de sus obras que Guarino Veronese y Giovanni Aurispa traen a Occidente desde Constantinopla. La editio princeps, en griego, se hace en Florencia en 1460 y empieza a ser traducido al latín desde 1470. ${ }^{39}$ En 1503 aparece la edición de Aldo Manuzio. Coincidiendo en Inglaterra, Moro y Erasmo, deciden también traducir algunas de sus obras. El resultado son cuatro versiones de Moro y cinco de Erasmo, que salieron después en París, en 1506, bajo el título de Luciani opuscula. 40 Es evidente que el mordaz escritor asiático es uno de los preferidos de ambos humanistas, y que ejerce sobre ellos una innegable influencia. Erasmo pensaba que Luciano servía para fustigar los vicios además de ser gracioso, y seguramente algo parecido se propondría con su Moria. La edición de Utopia hecha en Basilea por Froben aparece junto con las traduciones de Luciano hechas por el propio Moro, lo cual indica que las obras se concebían como pertenecientes a un mismo género. 41

Es evidente que la Utopia de Moro tiene suficientes componentes satíricos como para poder considerarla dentro de la tradición menipea. ${ }^{42}$ Paralelamente, también se ha escrito que la obra participa de lo esencial de la literatura bufonesca. ${ }^{43} \mathrm{Si}$ unimos ahora esos elementos al de la cultura carnavalesca, en tanto que manifestación folclórico-espiritual y modo de concebir el mundo, se forma un triángulo que demarca el territorio que en el que se sitúa la creación del humanista inglés.

Sátira menipea $\searrow$

\section{$\nVdash$ Literatura bufonesca}

\section{Utopia}

$\Uparrow$

\section{Carnaval}

Se conoce como sátira menipea un grupo de obras que mezclan prosa y verso y que recogen la herencia de Menipo de Gadara, filósofo cínico del III a. C, herede-

39 Cf. Trapp (1991), esp. p. 52.

40 Cf. Rummel (1985), pp. 49 y ss.

41 Cf. Trapp (1991), p. 57.

42 Cf. Jameson (2007), pp. 33 y ss; Heiserman (1963); Valdés (2006), pp. 179-207; También se puede consultar, entre otros, Smet (1996), Köppenfels (1982); Kristeller (1982), p. 15, relaciona explícitamente Utopia con Platón, Cicerón y Luciano.

43 Por ejemplo Huerta Calvo (1985-86). 
ro del espíritu de Diógenes el Perro, y del que prácticamente no se ha conservado ninguna obra. El testigo de Menipo lo toma Varro, pero por desgracia sus obras tampoco se conservan. También se incluyen en el desarrollo antiguo del género a Séneca, sobre todo por su obra Apocolocyntosis, a Luciano de Samosata (lo mismo que Menipo, de procedencia asiática), y posteriormente a Marciano Capela, Juliano, Macrobio y Boecio, entre otros. Esta tradición renace a partir de los siglos XV y XVI con obras como las de Erasmo o Justo Lipsio, que publica en 1581 su Satyra Mennipea, Somnium, Lusus in nostri aevi criticos. Sabida es la influencia de Lipsio en Quevedo, que podría añadirse a la nómina con sus Sueños, pero además podemos considerar como más o menos cercanos al género a muchos otros autores, desde Rabelais a Voltaire pasando por Alfonso de Valdés, Villalón, Vives, Bruno, Boccalini o Komenský. 44

En opinión de Relihan, el rasgo característico de la sátira menipea no es la mezcla de verso y prosa, sino que ese rasgo estilístico refleja una característica más esencial: "it is a genre that desires that nothing be taken too seriously". 45 En general, se trata de uno de esos géneros de difícil definición, porque su misma esencia es la reunión de contrarios y la mezcla desordenada de cosas. Podría decirse que es una especie de antigénero, que engloba una literatura que gusta de reírse de la propia tradición en la que se inserta. O sea, de una literatura irreverente que se ríe de todo lo sagrado o autorizado por una tradición determinada, o que gusta ponerlo en duda a través de los más diversos mecanismos y teniendo en cuenta la inestabilidad de las verdades de los hombres. Por eso Norden considera a Luciano de Samosata como a uno que "Hohes und Heiliges ins Frivole gezogen hat". 46 Es decir, una toma de posición eminentemente cínica y cercana también al espíritu de los escépticos, que consideran que el ser humano no puede acceder a la verdad. Consecuentemente, como dice al final de su diálogo Necycomantia el mismo Luciano, es mejor no preocuparse de nada, ${ }^{47}$ una actitud paralela a la preferencia final de Cándido, según el cual "il faut cultiver notre jardin".

Es normal que Luciano de Samosata se convirtiera en autor preferido de quienes, en el siglo XVI, se proponían reformar las instituciones y la espiritualidad de la cristiandad. La Reforma depende, por un lado, de un movimiento puramente filológico, derivado del progreso del conocimiento del griego en parte gracias a la caída de Constantinopla y la emigración de eruditos y manuscritos bizantinos, y que repercute en un acercamiento radicalmente nuevo al texto bíblico; pero, por otro lado, recoge la herencia medieval de búsqueda de una nueva sensibilidad y de una nueva concepción religiosa con vistas a superar las contradicciones que la Iglesia

\footnotetext{
${ }^{44}$ Cf. Riikonen (1987); Relihan (1993); Marsch (1998), Sánchez (2005).

45 Relihan (1993), p. 22.

46 Norden (1923), p. 394.

${ }^{47}$ Cf. Relihan (1993), p. 22.
} 
había ido acumulando en los últimos siglos. Es decir, que la Reforma es un movimiento de filólogos que pretenden transformar las instituciones -y algunos acaban haciéndolo, como Lutero o Calvino. En este contexto, el espíritu crítico de Luciano, su lección de sarcasmo para con todo lo más venerando, sirvió a menudo de inspiración a quienes querían derribar los pilares de una sociedad corrupta para implantar una nueva visión del hombre. Por otra parte, la crítica social e institucional y la autocrítica y autoironía, la suspensión de los mecanismos de legitimación del discurso, llevan a la creación de la novela moderna, un género para el que, según Bajtin, tiene una importancia capital Luciano de Samosata, la figura del loco y del pícaro y la percepción carnavalesca de la vida. 48

Pero precisamente por el contexto mismo en el que nos estamos moviendo, la Reforma, entendida como movimiento del humansmo cristiano que busca una renovación de la Iglesia aunque no necesariamente su escisión, hay que poner límites al carácter cínico y pirronesco de Luciano en su recepción por parte de Erasmo y Moro. Tal y como lo lee Bracht, Moro es un escritor más bien ético, mientras que

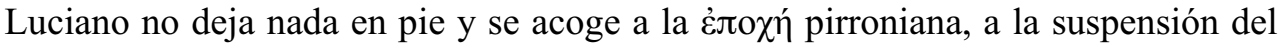
juicio y a la seguridad de que es mejor reírse de todo ya que ningún valor ni ningún significado perdura. ${ }^{4}$ Esta actitud radical no es ni la de Moro ni la de Erasmo, que no dudan de la Revelación; pero obras como Utopia o Encomium moriae no son obras teológicas. En ellas puede estar presente el espíritu del cristianismo, como hemos visto, pero también hay otro tema: la relación de unos hombres con otros en el seno de la sociedad, la pregunta por el sentido de los valores mundanos. Por eso puede encontrarse en tales obras dos tipos de sátira: el primer tipo se emplea para enseñar verdades, sátira crítica y educativa como pueden ser la de carácter anticlerical o la fustigadora de los vicios; pero la segunda es más profunda, remite al espíritu de Luciano y parte de la contemplación de que lo humano, por si mismo y sin la intervención de lo divino, carece de fundamento. 50 En lo que no afecta a las verdades evangélicas, las dos obras dejan ver el juego de ambigüedad y perspectivismo que grava el discurso del hombre en este mundo. Y, en el caso concreto de Utopia, la intervención del bufón y la aparición del autor al final cumplen la misma

48 Para la relación Bufón-Pícaro-Loco, con alusión a la cultura popular, remito al capítulo VI de Bajtin (1989), pp. 310 y ss. Sobre la importancia de Luciano bastará una frase: “[...] Samosata, patria de Luciano, que ha tenido un papel colosal en la historia de la novela europea", p. 431. Sobre la tradición carnavalesca en Cervantes, se pueden consultar varios de los trabajos de Redondo (1998). Existe una posible relación directa entre Erasmo y el carnaval, propuesta por Lefebvre (1968), pp. 67-68. Se trata de una defensa de la visión carnavalesca de la existencia que se encuentra en el Podalirij Germani cum Catone Certomio de furore germanico diebus genialibus carnisprivii Dialogus, de Theodoricum Gresemundum, publicado en 1495, y que Erasmo sigue de cerca. Ver también pp. 213 y ss.

49 Según Bracht (1985), el lucianismo verdadero reaparece en Europa sólo con Gargantúa. Yo creo que ya es detectable con Moro si tenemos en cuenta el discurso polifónico al que se ha aludido aquí.

50 Cf. Benda (1979), tesis doctoral inédita, p. 5. 
función que la que se ha considerado básica en el género menipeo, socavar la credibilidad del propio discurso, equiparando a Hythlodaeus con un bufón.

\section{Utopía e ironía}

Que existe una relación evidente entre sátira menipea y novela moderna parece obvio. Ambas se basan en la parodia de una poética dada, y expresan conscientemente la incertidumbre epistemológica en que se encuentra el hombre frente a la realidad de su propia discursividad en tanto que facultad que pretende representar una verdad.51 Pero lo que se pone en juego en la creación, a lo largo del siglo XVI, del nuevo lenguaje novelesco, no es sólo el mecanismo retórico, sino una determinada concepción del saber, alrededor de cuya problemática se ubica también el nacimiento del género de la utopía moderna. Es decir, novela y utopía nacen de un mismo suelo a lo largo del XVI.

Bajtin ha prestado atención especial a la influencia de Luciano en Rabelais como inspiración paródica; la parodia conduce a la novela polifónica en tanto que su lenguaje consiste en la recogida de voces diferentes que, en su actuación desjerarquizada, socavan el discurso único de la autoridad, sometiéndolo todo a la duda sistemática de la desaparición de las preferencias o privilegios en el acceso a la verdad. ${ }^{52} \mathrm{La}$ imagen que se da del mundo, probablemente una imagen que tenían muchos hombres, cultos o no, en la Europa de los siglos XV y XVI, es la de un desatinado caos de opiniones sin centro. Precisamente en la novela moderna encuentra Schlegel, según los famosos fragmentos publicados hacia 1800 en las revistas Lyceum y Athenaeum, lo que se conoce como ironía romántica. Schlegel, quien decía que "las novelas son los diálogos socráticos de nuestro tiempo" 53 , por una parte encontraba en ellas una sistemática auto-anulación de la propia credibilidad, y por otra parte "la conciencia clara de la movilidad eterna, de un caos que hormiguea hasta el infinito". 54

También encontramos en la Utopia moreana un socavamiento de la credibilidad del discurso de Hythlodaeus. La presencia del bufón, el narrador mismo como posible bufón, el juego absurdo de los nombres de la isla, la aparición final de Moropersonaje criticando lo dicho, el juego de espejos de la primera parte con la segunda y la introducción de prácticas grotescas y descabelladas en la sociedad de Utopía,

51 Cf. Bajtin (1989), esp. p. 186.

52 Para el trabajo de Bajtin sobre Luciano ver Riikonen (1987), pp. 27 y ss.; Relihan (1993), p. 23; así como los capítulos VII y VIII de Bajtin (1989), pp. 318 y ss.

53 Schlegel (1980), I, p. 167: "Die Romane sind die sokratischen Dialoge unserer Zeit." Es el Fragmento $\mathrm{n}^{\circ} 26$.

54 Schlegel (1980), I, p. 271: "Ironie ist klares Bewußtsein der ewigen Agilität, des unendlichen vollen Chaos" (de la sección Ideen, concretamente la n 69). Cf. Schoentjes (2003), pp. 87 y ss. 
todo ello, nos lleva de alguna manera ese "unendliches Chaos" en el que se encuentra sumido el hombre a la hora de la construcción de la sociedad. Consecuentemente, podría decirse que en la Utopia de Moro encontramos algo más parecido a la ironía romántica que a la construcción poética del estado ideal.

Deberían, pues, revisarse profundamente las convenciones genéricas que suelen aplicarse a esa tradición literaria y filosófica. Es lo que ya se había propuesto Louis Marin, que analiza la idea de lo utópico introduciendo los conceptos de neutralidad y límite. 55 Según Marin, Utopía es una isla que se encuentra situada en un espacio neutro: sirve de término de referencia en un lugar al que no se puede acceder. Es imposible ejercer juicios valorativos acerca de Utopía, sólo se pueden ejercer juicios desde ella, porque, en el fondo, ella no es el tema, sólo es el espejo en el que se refleja el tema, que somos nosotros. Por tanto, Utopía no representa tanto un lugar como el límite del lugar que ocupamos nosotros mismos. Al presentarse como lo que se encuentra más allá de lo que somos, establece nuestro límite porque se presenta como nuestro otro. La obra de Moro, entonces, no expresa una sociedad ideal, sino la misma dinámica de la representación y de la construcción del pensamiento y de la imagen que se tiene sobre uno mismo. Es un discurso acerca de la discursividad:

L'utopie est un discours, mais elle n'est pas le discours du concept: elle est le discours de la figure, un mode figuratif particulier du discours: fiction, affabulation, récits "anthropomorphisés" et descriptions "concrètes", roman exotique et tableau représentatif, autant de caractères qui lui sont propres. 56

El tema de la obra no es "el estado perfecto", sino la misma representación. No hay, por tanto, utopía, sino sólo una imagen como cualquier otra. Lo utópico, en Moro, no representa ningún ideal, sino un esquema. ${ }^{57}$ No existe lo ideal, por un lado, y la realidad, por otro. Lo (supuestamente) ideal no es más que un comentario que deja manifestarse lo real; está continuamente presente y va de la mano y desarrollándose paralelamente, y con una dinámica semejante, a lo que llamamos realidad.

En la misma dirección nos puede llevar el estudio de Mannheim. El investigador es perfectamente consciente de que en el desarrollo histórico de las sociedades, utopía e ideología no caminan sin dejar de entremezclarse; 58 y no obstante, propone una diferenciación conceptual. Lo que caracteriza a la ideología es que se trata de un discurso que oculta algo, que se presenta silenciando su verdadera finalidad. 59

\footnotetext{
55 Cf. Marin (1973 y 1993).

56 Marin (1973), p. 22.

57 Marin (1973), p. 26: "Au niveau de l'imagination, le discous utopique fonctionne non comme une icône, mais comme un schème."

58 Cf. Mannheim (1969), p. 177.

59 Mannheim (1969), pp. 53 y ss. Habría que preguntarse qué discurso presenta explícitamente todos sus móviles.
} 
La naturaleza de la utopía es su orientación hacia una ruptura del orden existente. Según Mannheim, la conciencia utópica está básicamente en desequilibrio con el ser -en su sentido socio-histórico.60 Pero la misma ideología también está en cierto modo en un estado de incongruencia con la realidad; como ejemplo de ello aduce que cumplir con el predicamento del amor cristiano al prójimo en la Edad Media, llevando esta conducta a su extremo, sería también una misión irrealizable. Por eso considera que lo que verdaderamente diferencia a lo utópico de lo ideológico no es tanto el carácter irreal de lo primero, que es lo que se ha constituido como una de sus connotaciones fundamentales en el empleo del término, sino su caracter transformador. Este carácter transformador no permite designar la utopía como concepción de un estado perfecto e ideal, que se opusiera a lo ideológico o a lo histórico en tanto que imperfecto y real; lo ideológico, en opinión de Mannheim, tampoco está completamente acordado con la realidad, aunque en última instancia se asimile más fácilmente al estado de cosas existente. Si la esencia de lo utópico es su carácter transformador, cinético, sólo puede darse en tanto que interconexión de pautas distanciadas entre sí: es una agencia real que interactúa con otras. Volvemos a la idea de Marin, según el cual lo utópico es la relación entre límite y espacio. Si utopía es transformación, entonces es relación, y consecuentemente no es una entidad, sino la comunicación que se produce entre entidades -a través del discurso en tanto que lenguaje y pensamiento. Por tanto la utopía ni es lo irrealizable ni es lo ideal, sino que es aquello que ahora, ya, está sucediendo en el intercambio simbólico de las sociedades. La aparente perfección con que se presenta a sí mismo el discurso utópico, por otra parte, lo reconvierte en ideología: oculta sus verdaderos objetivos. Lo utópico, en la concepción clásica del término, no aporta un plan perfecto -¿qué es perfecto? ¿según quién?- sino una configuración de la que se predica que es perfecta o ideal a fin de que pueda realizar un rendimiento transformador, que es lo que verdaderamente importa, y que no se sabe si va a ser posible hasta que se impone y entonces vuelve a segregar su discurso.

Volviendo al caso de Moro, podría decirse que lo que su libro propone es, precisamente, dejar al descubierto el hecho de que su utopía es, en tanto que discurso, una imposición subjetiva que busca promoverse a través del ocultamiento de algunas de sus motivaciones y finalidades ( $i$ se ha reflexionado sobre las motivaciones personales de Hythlodaeus?); un discurso que en el proceso mismo de su formación y enunciación encuentra las contradicciones internas de su sentido; en definitiva, una verdad humana, lanzada en el contexto del diálogo, que es donde debe imponerse -y si lo hará o no no depende de su grado de idealización, sentido común o conveniencia, de su grado de "verdad", sino del intercambio simbólico-político de los actuantes, mutuamente interpretadores y jueces de lo que se dice. No creo que

60 Mannheim (1969), p. 169: "Utopisch ist ein Bewußtsein, das sich mit dem es umgebenden Sein nicht in Deckung befindet." 
sea correcto decir que la Utopia de Moro se convierta en instrumento revolucionario, aplicándole la conceptualización de Mannheim. ${ }^{61} \mathrm{El}$ sociólogo no pretende aclarar la obra del humanista inglés y es consciente que escapa a los límites formales de su estudio. $62 \mathrm{El}$ impulso de esa obra no es la transformación de la sociedad o del orden establecido -si lo fuera no tendría sentido que Moro presentara su propia doctrina sometida a la ironía, la autoparodia y la desconfianza. Si toda utopía, según Marin, es juego de territorio y límite, podemos decir que el libro de Tomás Moro es la escenificación de la consciencia de este hecho.

La concepción de la utopía como propuesta de un estado ideal se basa, posiblemente, en una lectura errónea de la primera obra que inaugura su tradición moderna. Occidente ha necesitado y sigue necesitando un modelo no real para lo real. La obra de Moro dice que todo modelo "ideal" es también "real", y, por tanto, sometido a la inestabilidad propia de lo que existe, de lo que se enuncia. En este sentido, está mucho más cerca del espíritu que anima el surgimiento de la novela moderna, en la encrucijada Ariosto-Rabelais-Cervantes, puesto que participa de los mismos fundamentos: carnaval, humanismo, crítica reformista, secularización, relativismo, ironía lucianesca, etc. Aquello que se nos presenta como utópico ¿no es en el fondo lo que alguien dice que es utópico? Tiene la misma sustancia que cualquier cosa que se le pasa por la cabeza a un personaje, y luego lo actúa.

\section{Referencias bibliográficas}

BAJTin, M. (1989): Teoría y estética de la novela, Madrid, Taurus.

Benda, F. J. (1979): The Tradition of Menippean Satire in Varro, Lucian, Seneca and Erasmus, Austin, The University of Texas Press.

Biesterfield, W. (1982): Die literarische Utopie, Stuttgart, Metzler.

Blaim, A. (1982): “More's Utopia: persuasion or polyphony?", Moreana, 73, pp. 520.

Blanco Martínez, R. (1999): La ciudad ausente. Utopía y utopismo en el pensamiento occidental, Madrid, Akal.

CALVERT, Brian (1987): “Slavery in Plato's Republic”, Classical Quaterly, 37, pp. 367-372.

Campanella, T. (1962): Cittá del sole e poesie, Milano, Feltrinelli.

Cuffel, Victoria (1966): "The Classical Greek Concept of Slavery", Journal of the History of Ideas, 27, pp. 323-342.

Foucault, M. (1964): Histoire de la folie a l'âge classique, París, Union Générale d'Éditions.

${ }^{61}$ Cf. Martínez Elipe (2007), esp. pp. 89 y ss.

62 Mannheim (1969), p. 175. 
Frye, N. (1982): "Diversidad de utopías literarias", en Frank E. Manuel (ed.), Utopías y pensamiento utópico, Madrid, Espasa Calpe, pp. 55-81.

Grondin, J. (1991): Einführung in die philosophische Hermeneutik, Darmstadt, Wissenschaftliche Buchgesellschaft.

HARRIS SACKS, D. (1999): "Introduction", en Sir Thomas More, Utopia, Bedford, Boston-Nueva York, pp. 1-79.

HeIDEgGer, M. (1977): Sein und Zeit, Tübingen, Max Niemeyer.

HeidegGer, M. (2003): "Nietzsches Wort »Gott ist tot«", en M. Heidegger, Holzwege, Frankfurt, Klostermann, pp. 209-267.

Heiserman, A. R. (1963): "Satire in the Utopia", Papers of the Modern Language Asociation, 78, pp. 163-174.

Hexter, J. H. (1952): More's Utopia. The biography of an idea, Princeton, Princeton University Press.

Huerta CAlvo, J. (1985-86): "Stultifera et festiva navis (De bufones, locos y bobos en el entremés del siglo de oro)", Nueva revista de filología hispánica, 34, pp. 691-722.

JAMESON, F. (2007): Archaeologies of the future: the desire called Utopia and other Science Fictions, Londres y Nueva York, Verse Books.

JONES, H. (1989): The epicurean tradition, Londres y Nueva York, Routledge.

KAISER, W. (1963): Praisers of Folly. Erasmus. Rabelais. Shakespeare, Cambridge, Harvard University Press.

KAUTSKY, K. (1959): Thomas More and his Utopia with a historical introduction, Nueva York, Russell \& Russell.

Koppenfels, W. von (1982): "Thomas Morus und die humanistische Utopie der Renaissance", en Manfred Pfister (ed.), Alternative welten, Munich, Fink, pp. 96-113.

KoubA, P. (2001): Smysl konečnosti, Praga, Oikúmené.

KoubA, P. (2006): Nietzsche. Filosofická interpretace, Praga, Oikúmené.

KoubA, P. (2009): El mundo según Nietzsche, trad. Juan A. Sánchez, Barcelona, Herder.

Kristeller, P. O. (1982): “Thomas Morus als Humanist”, en Dieter Wuttke (ed.), Thomas Morus als Humanist, Bamberg, Kaiser Verlag, pp. 9-37.

KŘížovÁ, M. (2007): "Christian Churches and Slavery in the New World: A Comparative Perspective", Acta Comeniana, 20-21, pp. 65-103.

LeFEBVRE, J. (1968): Les fols et la folie, Etude sur les genres du comique et la création littéraire en Allemagne pendant la Renaissance, París, Klincksieck.

Mannheim, K. (1969): Ideologie und Utopie, Frankfurt, Schulte-Bulmke.

MANUEL, F. E. (1982): "Hacia la historia psicológica de las Utopías", en Frank E. Manuel (ed.), Utopías y pensamiento utópico, Madrid, Espasa Calpe, pp. 103135. 
MARIN, L. (1973): Utopiques: jeux d'espaces, Paris, Minuit.

MARIN, L. (1993): "Frontiers of Utopia: Past and Present", Critical Inquiry, 19, pp. $397-420$.

Márquez VillanueVA, F. (1982): "Jewish »fools« of the spanish fifteenth century", Hispanic Review, 50, pp. 385-409.

Márquez Villanueva, F. (1985-86): "Literatura bufonesca o del 'loco'“, Nueva Revista de Filología Hispánica, 34, pp. 501-528.

Marsch, D. (1998): Lucian and the latins, Ann Arbor, The Michigan University Press.

MARTínez EliPe, L. (2007): Idea de la historia. Ideología, utopía y realidad, Madrid, Biblioteca nova.

Moro, T. (1518): Utopía [De optimo reip. statu deque nova insula Utopia libellus vere aureus, nec minus salutatis quam festivus, clarissimi disertissimique viri Thomae Mori inclytae civitatis Londinensis civis \& Vicecomitis], Basilea, Froben.

Nelson, E. (2001): “Greek Nonsense in More's Utopia”, The Historical Journal, 44, pp. 889-917.

Norden, E. (1923): Die Antike Kunstprosa, Leipzig-Berlín, Teubner.

PÉrez, J. (2004): Las comunidades de Castilla, Madrid, Alba libros.

Prevost, A. (1971): “L’Utopie: le genre littéraire”, Moreana, 31-32, 161-168.

RotTerdam, E. de (1551): Moriae encomium, Basilea, Froben.

RotTerdam, E. de (1906-1958): Opus Epistolarum Des. Erasmi Roterodami, Oxford, Clarendon Press.

RotTERDAm, E. de (2006): O svobodné vi̊li, (De libero arbitrio), Praga, Oikúmené.

RABElais, F. (2007): Gargantua, París, Gallimard.

Redondo, A. (1998): Otra manera de leer el Quijote, Madrid, Castalia.

Relihan, J. C. (1993): Ancienit Menippean Satire, Baltimore-Londres, The John Hopkins University Press.

RiIKonen, H. K. (1987): Menippean Satire as a Literary Genre; with Special Reference to Seneca's Apocolocyntosis, Helsinki, Societas Scientiarum Fennica.

Rummel, E. (1985): Erasmus as a Translator of the Classics, Toronto-BuffaloLondres, The University of Toronto Press.

SAN JuAn, H. de (1989): Examen de ingenios, Madrid, Cátedra.

SÁnchez, Juan A. (2005): "Parallele Motive bei Johann Amos Comenius und Baltasar Gracián”, Acta Comeniana, 19, pp. 37-69.

SchlAIFER, R. (1936): "Greek Theories of Slavery from Homer to Aristotle", Harvard Studies in Classical Philology, 47 , pp. 165-204.

Schlegel, F. (1980): Werke in zwei Bänden, Berlin, Aufbau.

Schoentues, P. (2003): La poética de la ironía, Madrid, Cátedra.

SERVIER, J. (1969): Historia de la Utopía, Caracas, Monte Ávila.

SMET, I. (1996): Menippean Satire and the Republic of letters, 1581-1655, Ginebra, Droz. 
SylveSteR, R. S. (1977): “»Si Hythlodaeo Credimus«: Vision and Revision in Th. More's Utopie", en Richard S. Sylvester y G. P. Marc'adow (ed.), Essential Articles for the study of Thomas More, Hamdem, Archon Books, pp. 290-301.

TATLOCK, J. S. P. (1943): “Geoffrey of Monmouth's Vita Merlini", Speculum, 18, pp. 267-287.

Trapp, J. B. (1991): Erasmus, Colet and More: The Early Tudor Humanists and their Books, Londres, The British Library.

VAssberg, D. E. (1986): Tierra y sociedad en Castilla; Señores, "poderosos" y campesinos en la España del siglo XVI, Barcelona, Crítica.

Vlastos, G. (1968): "Does Slavery Exist in Plato's Republic?", Classical Philology, 63, pp. 291-295.

Welsford, Enid (1968): The Fool. His Social and Literary History, Londres, Faber \& Faber.

Juan Antonio Sánchez

Universidad Carolina de Praga

sanchez@praha1.ff.cuni.cz 